\title{
XLIII. On the determination of chemical affinity in terms of electromotive force.-Part II
}

\section{C.R. Alder Wright D.Sc.Lond. \& E.H. Rennie M.A. B.Sc.}

To cite this article: C.R. Alder Wright D.Sc.Lond. \& E.H. Rennie M.A. B.Sc. (1880) XLIII. On the determination of chemical affinity in terms of electromotive force.-Part II, Philosophical Magazine Series 5, 9:57, 331-347, DOI: 10.1080/14786448008626850

To link to this article: http://dx.doi.org/10.1080/14786448008626850

曲 Published online: 28 Apr 2009.

Submit your article to this journal $₫$

Џ Article views: 2

Q View related articles $\square$ 
XIIII. On the Determination of Chemical Affinity in ternzs of Electromotive Force.-Part II.* By C. R. AlDER W RIGHT, D.Sc.Lond., Lecturer on Chemistry and Physics, and E. H. Rennie, M.A. (Syd.), B.Sc. (Lond.), Demonstrator of Chemistry in St. Mary's Hospital Medical School.

Experimental Determination of the Electromotive Force corresponding to the Work done in the Decomposition of Water into Oxygen and Hydrogen at the ordinary temperature.

38. TN order to apply the principles described in Part I. $1(\$ 11,18,32)$, the current from a Daniell battery was passed through a voltameter placed in a calorimeter, and the average difference of potential between the voltameterplates determined by connecting them with a quadrant electrometer standardized by a Clark cell (verified for us by Dr. Alexander Muirhead). The amount of decomposition being determined ( $=n$ grammes), and the quantity of heat, $h$, developed in the voltameter observed, the data were obtained for the calculation of the E.M.F. representing the nett work corresponding to the sum of the physical and chemical changes taking place by the formula

$$
e=\mathrm{E}-\frac{h a \chi \mathrm{J}}{n},
$$

$a$ being the equivalent of the electrolyte.

In the case of water acidulated with sulphuric acid, the following results were obtained. The voltameter consisted of a wide test-tube of about 30 millimetres diameter, into the neck of which was fixed an india-rubber cork perforated with three holes: through the centre one passed a delivery tube of small bore for the collection of the evolved gases; through the other two, copper rods 5-6 millims. in diameter. To the lower ends of these were soldered equally thick platinum rods, the free ends of which were previously forged into spade-like plates which were arranged parallel to one another; the solderings and the portions of the copper rods inside the test-tube were imbedded in a thick mass of gutta-percha, with the threefold object of keeping the plates at an invariable distance from one another (the voltameter being also intended for some other experiments in which this was essential), of protecting the copper and soldering from corrosion by the acid and the consequent introduction of metals into the solution electrolyzed, and of filling up the upper space in the tube, so that any error due to alteration in temperature of the voltameter and conse-

* Part I., suprì, pp. 237-266.

$2 \mathrm{~B} 2$ 


\section{Messrs. Wright and Rennie on the Determination of}

quent retention therein of varying quantities of gas should be rendered negligible. The projecting ends of the rods were passed through small india-rubber corks and amalgamated; by then fixing short pieces of wide glass tubing over these smaller corks and pouring mercury into the cups thus formed, connexion by mercury-cups could readily be established between the battery and the voltameter-plates.

This arrangement of mercury-cups was also applied to the copper Daniell-battery cells, a thick wire bent downwards and amalgamated at the end being also soldered to each zinc plate so as to dip into the mercury-cup of the next cell. Much trouble in brightening connexions \&c. was thus saved; the current could readily be broken instantaneously by simply lifting one of the zinc plates an inch or so, so that the wire no longer dipped into the mercury ; whilst an easy means was afforded of introducing more cells or shutting some out from the circuit when required without actnally interrupting the current.

39. A number of attempts were made to utilize Bunsen's ice-calorimeter for the measurement of the heat evolved; the construction of apparatus sufficiently large to enable considerable amounts of heat to be measured accurately, however, was found to present some difficulties; whilst with smaller apparatus the errors of measurement of the amount of gas evolved became considerable, even when the voltameter was connected with the gas-measuring apparatus used for Frankland and Armstrong's water-analysis process; for the occlusion of the evolved gases by the electrodes, the absorption of oxygen by the acidulated water of the voltameter, the production of ozone or of hydrogen dioxide, and the removal of hydrogen whilst still nascent from the one electrode by combination with dissolved oxygen, and of oxygen from the other by combination with dissolved hydrogen, present sources of diminution in the amount of gas actually evolved, which mostly become relatively greater with weak currents, such as would have to be employed with a small ice-calorimeter. Although it did not appear to be impracticable to overcome these difficulties, yet it was found that to do so would require a considerable amount of time and trouble; and therefore we reverted to the use of an ordinary water-calorimeter, employing currents of sufficient magnitude to furnish upwards of $500 \mathrm{cub}$. centims. of mixed gases during the time which the experiment lasted (from ten to forty-five minutes, according to the battery power used). Even with the strongest currents used, representing about 0.65 C.G.S. current-unit, the amount of substances formed capable of liberating iodine from potassium iodide corresponded to no more than $\cdot 001$ to $\cdot 002$ gramme of 
iodine per $500 \mathrm{cub}$. centims. of gas produced, representing a diminution in the volume of gas evolved practically quite inappreciable. The gas-measuring apparatus in our possession being incapable of measuring so large a quantity as $500 \mathrm{cub}$. centims., we employed the method used by Joule for determining the volume of gas produced, viz. collection over water in a bottle, the weight of which was known when filled with water and closed by a stopper. To determine the gas collected, the bottle was immersed for some minutes in a large bucket of water, the temperature of which was known; when the gas had attained the temperature of the water, the bottle was raised until the level of the fluid inside and out was the same (i.e. until the pressure was atmospheric); the stopper was then inserted and the bottle removed, wiped dry, and weighed. In this way a close approximation to the quantity of gas produced was obtained, the error being one of defect, owing to the sources above mentioned and the absorption of oxygen by the water during the process of collection. From the number of cub. centims. of mixed gases thus obtained (reduced to dryness, $0^{\circ} \mathrm{C}$., and 760 millims.) $=v$, the weight of water decomposed, $w$, was calculated by the formula

$$
w=v \times 0.0005363 \text {, }
$$

the coefficient 0.0005363 being deduced from Regnault's observations that 1 litre of dry hydrogen and oxygen at $0^{\circ}$ and 760 millims. weigh respectively 0.089578 and $\mathbf{1 * 4 2 9 8 0 2}$ gramme,

whence 2 grammes of hydrogen occupy and 15.96 " oxygen " $11 \cdot 162 "$

so that 17.96 grammes of detonating gas occupy 33.489 ", or $1 \mathrm{cub}$. contim. of detonating gas weighs $\frac{17 \cdot 96}{33489}=0 \cdot 0005363$
gramme.

40. The calorimeter employed in these experiments consisted of a glass beaker capable of holding about $1500 \mathrm{cub}$. centims., fitted closely inside a polished tin cylinder supported (on a wooden block and several folds of wadding) concentrically inside a similar tin cylinder, so that about an inch of airspace everywhere intervened between the two tin surfaces, the two tin cylinders being kept in the same relative positions by cork wedges. This outer cylinder was weighted with lead and sunk inside a third similar larger cylinder filled with water; so that the calorimeter itself was surrounded on all sides, saving the top, by a water jacket. Polished tin lids for the calorimeter and the outermost vessel were provided, perforated with holes for the passage of the voltameter (in the axis of the cylinders), 


\section{Messrs. Wright and Rennie on the Determination of}

of the thermometers employed, and of the stirrers; these latter consisted of annular horizontal metallic plates, with stout vertical wires attached, so that by moving them up and down a very effective agitation could be accomplished. The thermometers were graduated in millimetres, and were carefully calibrated and checked against one another and against a Kew-standardized thermometer. The one used for the inner vessel was found to be sensibly uniform in calibre at the part where the observations were made (chiefly that corresponding to $12^{\circ}-20^{\circ} \mathrm{C}$.); and at this part the value of $1^{\circ} \mathrm{C}$. was 11.28 millims. Several careful determinations of the water-equivalent of the calorimeter (including the stirrer, thermometerbulb, and voltameter, which always contained 20 grammes of acidulated water containing 22 per cent. of $\mathrm{H}_{2} \mathrm{SO}_{4}$,) gave numbers varying from 1092 to 1097 , and averaging $1094 \cdot 5$ grammes when 1000 grammes of water (weighed in a vacuum) were placed therein.

41. In order to obtain with as great a degree of accuracy as possible the corrections for radiation with this instrument, a large number of observations were made of the rate of alteration of the reading of the calorimeter-thermometer under various conditions, viz. when the water jacket was hotter or colder than the calorimeter, and when the calorimeter was warmer or colder than a thermometer-bulb placed a few inches above the outer lid, so as to indicate the temperature of the air together with the effect produced by radiation from the hand during stirring. It was found that all the observations could be expressed with a fair degree of accuracy by the formula

$$
x=0 \cdot 16(\mathrm{M}-m)+0 \cdot 0225 \mathrm{~N},
$$

where $x$ is the alteration of the calorimeter-temperature (loss of heat) in millimetres per hour, $M$ the difference between the average readings of the calorimeter and water-jacket thermometers during the period of observation, $m$ a small correction (derived from a specially constructed table) to reduce the scalereading of the second of these thermometers to that of the first, and $\mathrm{N}$ the difference between the average temperature of the calorimeter and that of the air, as indicated by the third outer thermometer and expressed in terms of the scale of the calorimeter-thermometer. Thus, for example, the following table illustrates the observed and calculated values of $x$. It is noticeable, en passant, that whilst the heating or cooling effect of the air on the calorimeter exerted through the double lid is, for equal differences of temperature, much less than that of the water jacket, it is still not negligible, amounting to about $\frac{1}{7}$ of that of the jacket. 


\begin{tabular}{|c|c|c|c|c|c|c|c|}
\hline \multicolumn{2}{|c|}{$\begin{array}{l}\text { Water jacket } \\
\text { warmer than } \\
\text { room. Calori- } \\
\text { meter colder } \\
\text { than jacket } \\
\text { and warmer } \\
\text { than room. }\end{array}$} & \multicolumn{2}{|c|}{$\begin{array}{l}\text { Water jacket } \\
\text { colder than } \\
\text { room. Calo- } \\
\text { rimeter colder } \\
\text { than jacket and } \\
\text { colder than } \\
\text { room. }\end{array}$} & \multicolumn{2}{|c|}{$\begin{array}{l}\text { Water jacket } \\
\text { colder than } \\
\text { room. Calori- } \\
\text { meter slightly } \\
\text { warmer than } \\
\text { jacket and } \\
\text { colder than } \\
\text { room. }\end{array}$} & \multicolumn{2}{|c|}{$\begin{array}{l}\text { Water jacket } \\
\text { colder than } \\
\text { room. Calori } \\
\text { meter warmer } \\
\text { than jacket } \\
\text { and slightly } \\
\text { colder than } \\
\text { room. }\end{array}$} \\
\hline Obs. & & Obs. & & Obs. & & Obs. & Calc. \\
\hline $\begin{array}{l}-4.8 \\
-4.0 \\
-3.6 \\
-3.2 \\
-2.4 \\
-1.5 \\
-0.9 \\
-0.1 \\
+0.9 \\
+1.2 \\
+1.5 \\
+1.8\end{array}$ & $\begin{array}{c}-4.9 \\
-4.1 \\
-3 \cdot 6 \\
-2.7 \\
-2.0 \\
-1.3 \\
-0.7 \\
0 \\
+0.7 \\
+1.3 \\
+1.8 \\
+2.1\end{array}$ & $\begin{array}{l}-8 \cdot 0 \\
-7 \cdot 4 \\
-7 \cdot 0 \\
-5 \cdot 1 \\
-4 \cdot 8 \\
-4 \cdot 3 \\
-38 \\
-3 \cdot 6\end{array}$ & $\begin{array}{l}-8 \cdot 2 \\
-7 \cdot 3 \\
-6 \cdot 7 \\
-5 \cdot 4 \\
-4 \cdot 8 \\
-4 \cdot 3 \\
-3 \cdot 9 \\
-3 \cdot 5\end{array}$ & $\begin{array}{l}+0.2 \\
-0.2 \\
-0.7 \\
-1.0 \\
-1.5 \\
-1.4 \\
-1.0\end{array}$ & $\begin{array}{l}+0 \\
-0 \\
-0 \\
-1 \\
-1 \\
-1 \\
-1\end{array}$ & $\begin{array}{r}+2.3 \\
+1.9 \\
+1.2 \\
+1.0 \\
+0.8 \\
+0.3 \\
+0.2\end{array}$ & $\begin{array}{c}+2.3 \\
+1.9 \\
+1.4 \\
+1.3 \\
+0.8 \\
+0.3 \\
0\end{array}$ \\
\hline
\end{tabular}

42. It is evident from these numbers that the difference between the observed and calculated rates of alteration per hour rarely exceeds 0.2 millimetre, and averages much less; so that the difference between the results deduced by the formula and those attained by direct observation is practically negligible for all experiments lasting for only half an hour or less. In order, however, to diminish any error in the radiation-correction caused by the use of the formula, a threefold determination was made, as follows, the average of the three observations being taken. First, the correction was estimated from the observed average values of $\mathrm{M}$ and $\mathrm{N}$ throughout the experiment. Secondly, the rate of alteration of tomperature of the calorimeter (rising) before the experiment was commenced was determined by observations made for 30-60 minutes before commencing; and, similarly, the rate of alteration (falling) was determined by observations made for 30-60 minutes after concluding, and the mean of the two rates taken. Thirdly, the rate of alteration at the commencement of the experiment was calculated from the values of $\mathrm{M}$ and $\mathrm{N}$ then observed; and similarly the rate of alteration at the close was calculated from the then values of $M$ and $N$, and the mean taken as before. The three values rarely differed from their mean by so much as 0.1 millimetre per hour. Thus the following values were obtained in an experiment lasting eighteen 
minutes, the + value meaning loss of heat, and the - sign gain*.

$\left.\begin{array}{l}\text { Value of } x \text { obtained by first method } \\ \text { (formula applied to mean values of } \\ \mathrm{M} \text { and N) } . . \cdot . \cdot . \cdot .\end{array}\right\}$

Millims, per hour.

Value of $x$ obtained by second method.

Observed rate of alteration before experiment commenced

Observed rate of alteration after experiment concluded $+2 \cdot 0\}$

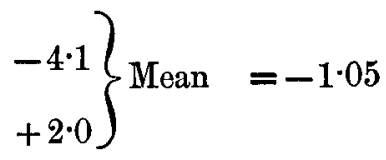

Value of $x$ obtained by third method.

Calculated rate of alteration at commencement . . . . $-4 \cdot 0$

Ditto at close . . . . . +1.95

$$
\}_{\text {Average }}=-1.02
$$

Hence the radiation-correction for the eighteen minutes during which the experiment lasted is $-\frac{18}{60} \times 1 \cdot 02=-0.31$.

43. The above correction, however, is not the only one to be applied; for the water in the voltameter gets beated more quickly than the calorimeter, and after the end of the experiment some time is required for the heat retained in the voltameter to become uniformly diffused throughout the calorimeter by passage through the glass wall of the voltameter. It was found that 6 or 7 minutes sufficed to bring about perfect equalization of temperature; so that during the first 5 minutes or so the temperature of the calorimeter slightly rose, and then began to fall again from the cooling effect of the radiation. Accordingly, to determine the true amount of rise in temperature during the experiment, the thermometer was read 8,10 , and 12 minutes after the conclusion-the loss by radiation during these several periods of 8,10 , and 12 minutes being added on to the observed temperature at the ends of these periods severally; the mean of the three numbers thus obtained was taken as the true temperature that would have been observed at the end of the experiment had the heat retained in the voltameter been diffused throughout the calorimeter at that moment. The loss during these three periods is calculated from the data in the latter two methods just

* This particular experiment is selected as an illustration because the temperature-corrections detailed in this and the subsequent paragraphs are larger than those in almost any other of the 18 experiments made in all (§ 46). 
described for the determination of the radiation-correction during the experiment: thus, in the illustration given, Observed rate of alteration after experiment concluded $+2 \cdot 0$
Calculated

$$
\text { " }
$$

"

$$
\text { Mean } \frac{+1.95}{+1.97}
$$

Hence the losses by radiation during 8,10 , and 12 minutes are respectively, $+0 \cdot 26,+0.33$, and +0.39 ; and the true rise in temperature of the calorimeter is found thus :-

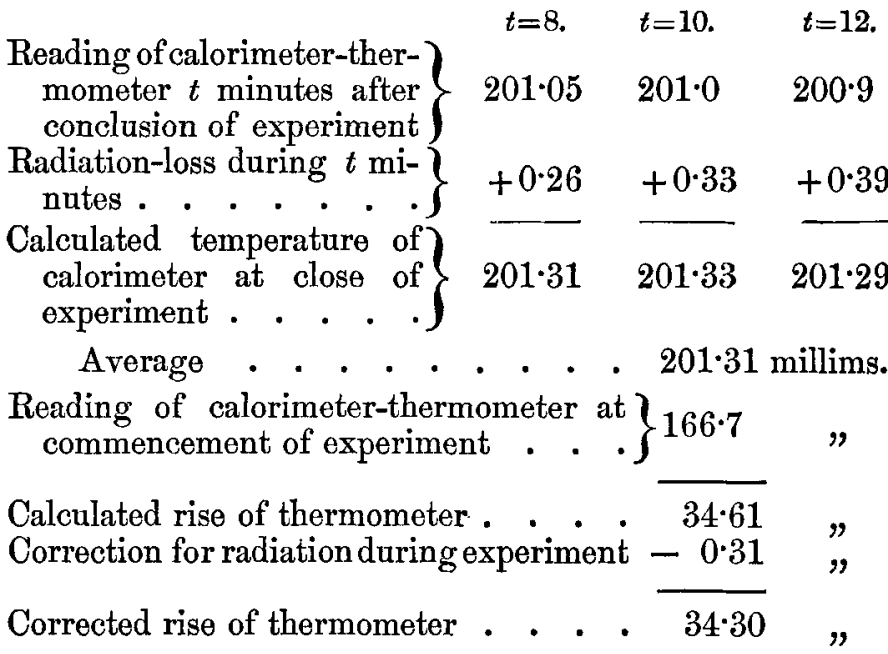

Since the water-equivalent of the calorimeter \&c. is 1094.5 , and 11.28 millims. of the thermometer-scale represent $1^{\circ} \mathrm{C}$., the amount of heat actually produced is

$$
\overline{34 \cdot 30} \times 1094 \cdot 5=3328 \text { gramme-degrees. }
$$

44. Two other small corrections also have to be applied to the heat-evolution thus determined. In the first place, the escaping gases pass out saturated with moisture, the evaporation of which absorbs a certain amount of heat. In each experiment the average temperature was close to $15^{\circ}$, at which temperature the tension of aqueous vapour is $1 \cdot 27$ centim. or $\frac{1 \cdot 27}{76}$ atmosphere, $=1 \cdot 67$ per cent. Hence every $1000 \mathrm{cub}$. centims. of evolved gas would contain $16.7 \mathrm{cub}$. centims. of water-vapour (at $0^{\circ}$ and 760 ), weighing 0.0134 gramme; the 


\section{Messrs. Wright and Rennie on the Determination of}

latent heat of water-vapour at $15^{\circ}$ being nearly 600 , this would represent very nearly 8 gramme-degrees per litre of evolved gases. Inasmuch as the gases were evolved not from pure water but from water containing 22 per cent. of sulphuric acid, it is likely that the gases actually evolved contained slightly less moisture than the normal saturating amount; but as in most of the experiments only about 500 to $550 \mathrm{cub}$. centims. of gases were evolved, the total correction is only about 4 gramme-degrees, and a trifling error in its estimation is negligible.

In the next place a minute amount of heat is absorbed in separating from sulphuric acid the water electrolyzed. From the experiments of Favre and Quaillard (Comptes Rendus, 1. p. 1150), 98 grammes of sulphuric acid already mixed with 216 of water (forming a dilute acid of composition $\mathrm{H}_{2} \mathrm{SO}_{4}+12 \mathrm{H}_{2} \mathrm{O}$ ) evolve 483 gramme-degrees when 72 grammes more of water are added (forming $\mathrm{H}_{2} \mathrm{SO}_{4}+16 \mathrm{H}_{2} \mathrm{O}$ ). The further addition of 72 grammes more of water evolves 222 gramme-degrees, whilst the addition of a third 72 grammes (forming $\mathrm{H}_{2} \mathrm{SO}_{4}+24 \mathrm{H}_{2} \mathrm{O}$ ) evolves 141 gramme-degrees. From these numbers, by interpolation, it results that acid of strength $\mathrm{H}_{2} \mathrm{SO}_{4}+20 \mathrm{H}_{2} \mathrm{O}$ (containing 22 per cent. of $\mathrm{H}_{2} \mathrm{SO}_{4}$ ) will evolve close upon 2.5 gramme-degrees when 1 gramme of water is added to such a quantity of acid as not sensibly to alter its composition by dilution; i.e. that for every gramme of water decomposed by electrolysis 2.5 gramme-degrees are absorbed.

In the experiment the calorimetric details of which have just been given, the corrected heat-evolution finally becomes as follows :-

Heat-evolution calculated from rise of thermometer corrected for radiation \&c. . . .

Correction for heat absorbed by moisture in $0 \cdot 4967$ grammo of mixed oxygen and hy- $\} \quad 9 \cdot 2$ drogen evolved during experiment . . .

gramme-degrees. 3328

Correction for heat absorbed in separating $0 \cdot 4967$ gramme of water from dilute sul- $\} \quad 1 \cdot 2$ phuric acid . . . . . . . . . .

$3338 \cdot 4$

45. The value of $\mathbf{E}$, the average difference of potential between the voltameter plates, was found thus. Before the experiment commenced the scale of the electrometer was standardized by means of a Clarke cell, several readings being taken by reversal so as to obtain total readings each equal to double the 
deflection; after the experiment was concluded the scale was again similarly standardized. The difference between the two standardizings was always very small or nil, but frequently was just perceptible, owing to leakage of electrometer charge; the mean of the two standardizings was taken to represent a potential diference of

$$
1.457\{1-(t-15) \times 0.0006\} \text { volt, }
$$

where $t$ is the Centigrade temperature, and 0.0006 the alteration in E.M.F. per $1^{\circ} \mathrm{C}$. (equal to 0.06 per cent. per $1^{\circ}$ ). As in the whole series of experiments taken together the average temperature of the cell was very close to $15^{\circ}$, the cell was assumed to have the constant average value 1.457 volt throughout. Throughout the experiment the potential difference between the electrodes was determined at as nearly as possible equal intervals of time by reversal, the quadrants being connected with the mercury-cups of the voltameter through the reversing-gear. As a general rule, the indicated potential-difference rose steadily throughout the experiment to the extent of from 3 to 6 per cent. of its initial value (owing to polarization of the electrodes); but in some cases this effect was just about compensated by a gradual diminution in current-strength, so that the potential difference remained nearly the same or slightly fell*. In the experiment the calorimetric details of which have just been given, the following values were obtained :-

Scaledivisions.

Value of Clark cell before experiment . . $80 \cdot 65$ $" \quad$ after $\quad$ Mean . . . . $\frac{.}{80 \cdot 60}$

Average of 23 pairs of readings of potential difference be-

* The fluctuations in the current and in the potential difference set up between the electrodes necessarily cause corresponding fluctuations in the amount of decomposition per second and the quantity of heat developed per second, and hence are allowed for, and (if not too great in extent) produce no effect at all on the end result. In just the same way, it is immaterial whether the electrodes are perfectly parallel and equal in size, whether the current passes more between their edges than between their centres, of what material they are made, and so on; for what is actually done is to measure the difference of potential between the mercury-cups at the ends of the thick copper rods connected with the electrodes, and also the quantity of electricity passing, and bence the total work doné between the cups. The resistance of the cups and thick copper rods being inappreciable, all this work must be done inside the voltameter between the electrodes, either as heat or chemical decomposition; the former being measured directly, the amount of the work representing the latter is known by difference. 
340 Messrs. Wright and Rennie on the Determination of

tween voltameter-plates (commencing with 237.5 and slowly sinking to $231 \cdot 0)=232 \cdot 40$.

Average potential-difference in volts,

$$
\frac{232 \cdot 40}{80 \cdot 60} \times 1 \cdot 457=4 \cdot 201 \text {. }
$$

Hence, taking $a=8.98, \chi=0 \cdot 000105$, and $J=42 \times 10^{6}$, the value of $e$ in the expression

$$
e=\mathrm{E}-\frac{h a \chi \mathrm{J}}{n}
$$

becomes $1 \cdot 540 \times 10^{8}$, since $\mathrm{E}=4 \cdot 201 \times 10^{8}, h=3338$, and $n=0 \cdot 4967$.

46. In precisely the same way the following numbers were obtained in seventeen other experiments.

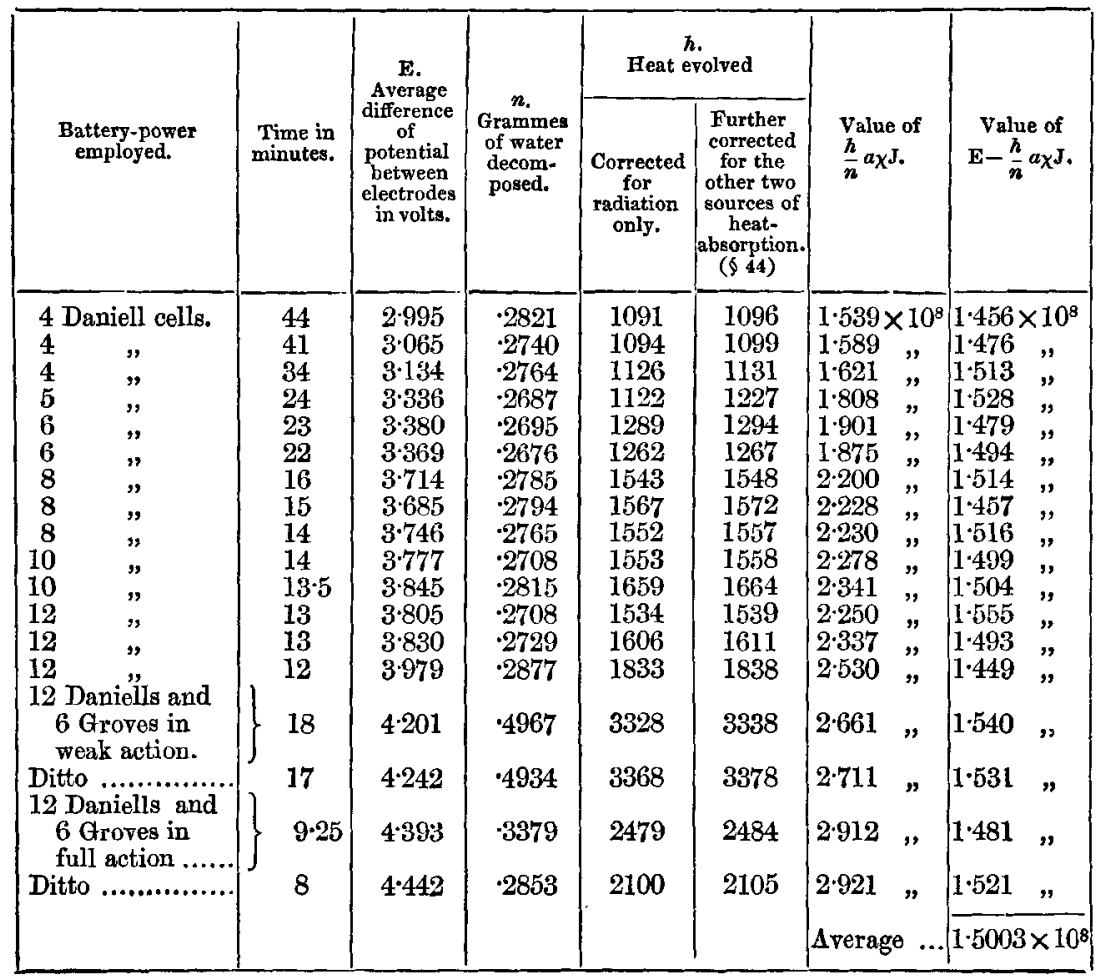


Maximum deviation

from mean.
On side of excess $\quad \frac{1.555-1.5003}{\mathbf{1 . 5 0 0 3}}=3.65$ per cent.

On side of deficiency $\frac{1.5003-1.449}{1.5003}=3.42 \quad$,

"Probable error" of one determination $\pm 0.0202=$

" $"$ result . . . $\pm 0.0048= \pm 0.32$

Experiments on a possible Source of Error in Joule's Valuation of $\mathbf{J}$ made in 1867 (Brit. Assoc. Reports).

47. The method used by Joule in these experiments consisted essentially in the comparison of the resistances of a platinum-silver wire (made into a coil and immersed in a calorimeter) and of copies of the B.A. unit, and then passing a current, measured by a tangent-galvanometer, through the coil and determining the amount of heat produced therein in a given time. The mean temperature of the calorimeter throughout a series of observations being determined, the resistance which the wire would possess at that temperature was calculated from the observed resistance at some other temperature, the rate of variation in resistance of the wire with temperature used being known. Calling this calculated resistance $\mathrm{R}$, the average current being $\mathrm{C}$, and the time $t$ seconds, the value of $J$ was deduced by the formula $J=\frac{\mathrm{C}^{2} \mathrm{R} t}{\mathrm{H}}$, where $\mathrm{H}$ is the heat evolved.

It is evident that any error in the valuation of $\mathbf{R}$ must produce an error to exactly the same extent in the value of $J$ thus deduced; and that such a source of error must have existed is evident from the circumstance that inasmuch as heat was continuously developed in the interior of the wire, and as an interval of time must necessarily elapse before heat could pass from the interior of the wire into the water by conduction, the temperature of the interior of the wire, and consequently the mean temperature of the wire as a whole, must have been somewhat higher than the mean temperature of the calorimeter. Apart from this, too, the wire must have been heated to a small extent above the whole mass of water in the calorimeter, owing to the adhesion to the wire of a film of warmed water which could not possibly be displaced by stirring absolutely pari passu with its becoming warmed. The very efficient automatic continuous stirring-arrangement adopted by Joule in the third series of investigations detailed in the paper referred to must necessarily have reduced this source of superheating of the wire to a minimum; but it is 


\section{Messrs. Wright and Rennie on the Determination of}

doubtful if it would wholly remove the additional tendency to superheating from this cause.

48. In order to form some idea of the possible extent to which the wire might thus become superheated by currents of the magnitude used by Joule*, a platinum wire about 50 centims. long and 1.15 B.A. unit resistance was twisted into a spiral, the ends of which were soldered to thick copper rods surmounted with mercury-cups and passing through an indiarubber cork to keep them together : this spiral was immersed in a beaker containing about a litre of distilled water, the temperature of which was read off to $0^{\circ} \cdot 1$ degree by a thermometer placed with its bulb almost touching the centre of the spiral ; by means of a broad horizontal ring of metal attached to a stout wire the water could be briskly agitated, to a much greater extent indeed than would be safe with a calorimeter in which splashing must be avoided. Currents of different strengths were then passed through the coil for periods of time varying from 20 minutes to an hour, a voltameter being also included in the circuit, and the total gas evolved collected as previously described. During this time the water was kept continually stirred, and its temperature observed at equal intervals of time, whilst the difference of potential existing between the ends of the wire was observed as frequently as possible by connecting the mercury-cups with a quadrant-electrometer standardized by a Clark cell before and after the experiment, precisely as above described. During the first two or three minutes the electrometer-readings always diminished through diminution of current by polarization of the voltameter-plates; afterwards they remained nearly constant, gradually rising through the increasing mean temperature of the wire, or slightly sinking if the current-strength diminished through continued use of the battery. During the first fow minutes the readings were accordingly taken every 10 or 15 seconds. without reversal, so as to obtain a large number of observations giving the mean potential difference during this period; subsequently the readings were taken by reversal at the rate of one pair per minute, the readings being divided into a

* In Joule's experiments the galvanometer made one turn only of 0.62723 foot radius, the angular deflection varying from $26^{\circ}$ to $32^{\circ}$; hence the currents must have lain between $\frac{0.62723 \times 30.48}{2 \pi}$. I. $\tan 26^{\circ}$ and $\frac{0.62723 \times 30.48}{2 \pi} .1 . \tan 32^{\circ}$, where 30.48 is the number of centims. in a foot and $I$ the horizontal terrestrial magnetic force. Taking $I=0 \cdot 18$, the currents must therefore have averaged about 0.3 C.G.S. unit. The resistance of the platinum-silver wire used was nearly equal to 1 B.A. unit $=10^{\circ}$ C.G.S. units, 
Chemical Affinity in terms of Electromotive Force. 343

number of groups corresponding to equal intervals of time ( 3 or 5 minutes), the average readings for each interval being again averaged to give the mean reading for the whole period; so that for an hour's observation more than 120 total readings were taken.

49. In this way the following numbers were obtained, the amounts of gas collected being translated into C.G.S. currentunits by the formula

$$
\mathrm{C}=\frac{\mathrm{V} \times 0.0005363}{\mathrm{~T} \times 60 \times 8.98 \times 0.000105}=\frac{\mathrm{V}}{\mathrm{T}} \times 0.09479,
$$

where $\mathrm{C}$ is the C.G.S. current, $\mathrm{V}$ the volume of gas (dry, at $0^{\circ}$ and 760 millims.), $T$ the time in minutes, and 0.0005363 the weight in grammes of a cubic centim. of mixed gases at $0^{\circ}$ and $760(\S 39)$; i. e. where $\frac{\mathrm{V}}{\mathrm{T}}$ is the volume of gas evolved per minute. The resistance of the wire is calculated from Ohm's law $\left(\mathrm{C}=\frac{\mathrm{E}}{\mathrm{R}}\right.$, whence $\left.\mathrm{R}=\frac{\mathrm{E}}{\mathrm{C}}\right)$ by dividing the average potential difference by the current. Every experiment was made as nearly as possible in the same way, so as to diminish sources of error and make the results comparable, the only noteworthy difference being that with the stronger currents shorter times were given, and the beaker of water in which the wire was immersed was slightly cooled at intervals during the experiment to avoid the temperature rising too high and having too wide a range.

\begin{tabular}{|c|c|c|c|c|c|c|c|c|c|c|}
\hline \multirow{2}{*}{$\begin{array}{l}\text { No. of } \\
\text { cells in } \\
\text { battery. }\end{array}$} & \multirow{2}{*}{$\begin{array}{l}\text { Time in } \\
\text { minutes. }\end{array}$} & \multirow{2}{*}{$\begin{array}{c}\text { Gas evolved } \\
\text { in cub. } \\
\text { cent., dry } \\
\text { at } 0^{\circ} \text { and } \\
760 \mathrm{~mm} .\end{array}$} & \multirow{2}{*}{$\begin{array}{l}\text { Average } \\
\text { G.C.S. } \\
\text { current. }\end{array}$} & \multicolumn{3}{|c|}{ Temperature of water. } & \multirow{2}{*}{\multicolumn{2}{|c|}{$\begin{array}{c}\text { Average } \\
\text { potential- } \\
\text { difference } \\
\text { in C.G.S. } \\
\text { units. }\end{array}$}} & \multirow{2}{*}{\multicolumn{2}{|c|}{$\begin{array}{c}\text { Resistance } \\
\text { in C.G.S. } \\
\text { units. }\end{array}$}} \\
\hline & & & & Initial. & Final. & Average. & & & & \\
\hline \multirow[t]{2}{*}{$\begin{array}{l}3 \\
\mathbf{3}\end{array}$} & \multirow[t]{2}{*}{$\begin{array}{l}60 \\
60\end{array}$} & \multirow{2}{*}{$\begin{array}{c}256 \cdot 6 \\
234^{\circ} 5 \\
\\
\text { A verage }\end{array}$} & $\begin{array}{l}0.0406 \\
0.0371\end{array}$ & \multirow[t]{2}{*}{$\begin{array}{l}8 \cdot 5 \\
7 \cdot 5\end{array}$} & \multirow[t]{2}{*}{$\begin{array}{r}10.0 \\
9.5\end{array}$} & $\begin{array}{l}9 \cdot 24 \\
8 \cdot 36\end{array}$ & \multirow{2}{*}{\multicolumn{2}{|c|}{$\begin{array}{l}0.4655 \times 10^{8} \\
0.4275 " ~\end{array}$}} & \multicolumn{2}{|c|}{$\begin{array}{l}1.147 \times 10^{9} \\
1.152 \quad "\end{array}$} \\
\hline & & & 0.03885 & & & 880 & & & $1 \cdot 1495$ & $"$ \\
\hline 4 & 30 & $244 \cdot 3$ & 0.0772 & $7 \cdot 9$ & $9 \cdot 2$ & $8 \cdot 50$ & \multicolumn{2}{|c|}{0.8931} & $1 \cdot 157$ & \\
\hline 6 & 30 & $461 \cdot 7$ & $0 \cdot 1459$ & $7 \cdot 4$ & $9 \cdot 0$ & $8 \cdot 20$ & $1 \cdot 697$ & & $1 \cdot 163$ & $"$ \\
\hline \multirow[t]{2}{*}{$\begin{array}{l}9 \\
9\end{array}$} & \multirow[t]{2}{*}{$\begin{array}{l}30 \\
20\end{array}$} & $\begin{array}{l}777.9 \\
493.4\end{array}$ & $\begin{array}{l}0.2458 \\
0 \cdot 2339\end{array}$ & $\begin{array}{l}7 \cdot 2 \\
7 \cdot 4\end{array}$ & $\begin{array}{r}11 \cdot 0 \\
9 \cdot 7\end{array}$ & $\begin{array}{l}9 \cdot 16 \\
8 \cdot 58\end{array}$ & \multirow{2}{*}{\multicolumn{2}{|c|}{$\begin{array}{l}2 \cdot 881 \\
2732\end{array}$}} & $\begin{array}{l}1 \cdot 171 \\
1 \cdot 168\end{array}$ & ", \\
\hline & & Average & 0.2398 & & ........ & $8 \cdot 87$ & & & $1 \cdot 1695$ & $"$ \\
\hline \multirow{3}{*}{$\begin{array}{l}12 \\
12\end{array}$} & \multirow{3}{*}{$\begin{array}{l}20 \\
20\end{array}$} & $624 \cdot 7$ & 0.2961 & $7 \cdot 1$ & $10 \cdot 1$ & $\begin{array}{r}8 \cdot 64 \\
0.18\end{array}$ & \multirow{3}{*}{$\begin{array}{l}3.469 \\
3.549\end{array}$} & \multirow{3}{*}{ ", } & $1 \cdot 172$ & , \\
\hline & & & & & & & & & & \\
\hline & & Average & $0 \cdot 2994$ & $\cdots$ & ....... & 8.91 & & & 1.172 & $"$ \\
\hline
\end{tabular}




\section{Messrs. Wright and Rennie on the Determination of}

Since the average temperature of the water surrounding the wire was nearly the same throughout, not differing by more than a few tenths of a degree from the mean $8^{\circ} .75$, the values in the last column are fairly comparable with one another; whence it is evident that a notable rise in resistance of the wire is produced by each successive increase in currentstrength. The resistance of the wire for a current of very small value would clearly lie under $1 \cdot 1495 \times 10^{9}$; so that the increase in resistance caused by currents of from 0.24 to 0.30 C.G.S. unit is at least $\frac{1 \cdot 1695-1 \cdot 1495}{1 \cdot 1495}$ to $\frac{1 \cdot 172-1 \cdot 1495}{1 \cdot 1495}$, or
$1 \cdot 7$ to $2 \cdot 0$ per cent.

50. In order to see what increase in mean temperature of the wire over that of the surrounding water this would represent, the fourth experiment was repeated, using warm water (at about $27^{\circ}$ ) to surround the coil: in this way the following numbers were obtained:-

\begin{tabular}{|c|c|c|c|c|}
\hline \multirow{3}{*}{$\begin{array}{l}\text { Water warmed } \\
" \text { cold }\end{array}$} & $\begin{array}{l}\text { C.G.S. } \\
\text { current. }\end{array}$ & $\begin{array}{l}\text { Average } \\
\text { emperature. }\end{array}$ & $\begin{array}{l}\text { Potential- } \\
\text { difference. }\end{array}$ & \\
\hline & & $\begin{array}{r}27 \cdot 25 \\
8 \cdot 20\end{array}$ & $\begin{array}{l}1 \cdot 716 \times 10^{8} \\
1 \cdot 697 \times 10^{8}\end{array}$ & $\begin{array}{l}1 \cdot 209 \times 10^{9} \\
1 \cdot 163 \times 10^{9}\end{array}$ \\
\hline & rence & $19 \cdot 05$ & & $0.046 \times 10^{5}$ \\
\hline
\end{tabular}

Since an increase in resistance of 0.046 corresponds to 19.05 degrees, an increase of 0.0200 to 0.0225 would correspond to 8.3 to $9 \cdot 3$ degrees; i.e. currents of $0 \cdot 24$ to $0 \cdot 30$ C.G.S. unit caused a superheating of the wire above the temperature of the surrounding water to an extent averaging $8^{\circ} .3$ to $9^{\circ} .3^{*}$. If it be admitted that in Joule's experiments a similar superheating to the extent of $8^{\circ}$ to $9^{\circ}$ may hare taken place, the effect on the calculated resistance of the platinum-silver used would be to cause the amount to be underestimated by about $8 \times 0.031$ $=0.25$ per cent. to $9 \times 0.031=0.28$ per cent., 0.031 being the percentage increase in resistance per degree of the alloy used by Joule (this alloy was purposely not used by the authors, in order to make the alteration in resistance, if any, more perceptible); that is, the value of J ultimately deduced would be about 0.25 to 0.28 per cent. too low.

51 . In order to see whether an increased amount of superheating would be produced by only stirring the water surrounding the wire at intervals of one or two minutes instead of continuously, some of the above observations were repeated

* This increase in resistance with temperature amounts to about 0.21 per cent. per $1^{\circ} \mathrm{C}$. Matthiessen found the average increase of pure metals to be about 0.37 per cent. per $1^{\circ} \mathrm{C}$., that of an alloy of platinum and iridium containing 33 per cent. of the latter being only 0.06 per cent. per $1^{\circ}$; probably, therefore, this platinum wire was somewhat impure, very likely containing iridium. 
under these conditions with the following results, clearly showing that whilst no very material influence is exerted by discontinuous stirring with weak currents, the effect is marked with currents of 0.23 to $0 \cdot 29$ C.G.S. unit.

\begin{tabular}{|c|c|c|c|c|c|}
\hline \multirow[b]{2}{*}{$\begin{array}{l}\text { Cells in } \\
\text { battery. }\end{array}$} & \multirow[b]{2}{*}{$\begin{array}{c}\text { Average } \\
\text { temperature. }\end{array}$} & \multirow[b]{2}{*}{$\begin{array}{l}\text { Average } \\
\text { current. }\end{array}$} & \multirow[b]{2}{*}{$\begin{array}{l}\text { Potential- } \\
\text { difference, in } \\
\text { volts. }\end{array}$} & \multicolumn{2}{|c|}{ Resistance } \\
\hline & & & & $\begin{array}{c}\text { at average } \\
\text { temperat ure } \\
\text { of } \\
\text { experiment. }\end{array}$ & $\begin{array}{c}\text { corrected to } \\
8^{\circ} \cdot 75 .\end{array}$ \\
\hline $\begin{array}{r}3 \\
6 \\
9 \\
12\end{array}$ & $\begin{array}{l}7 \cdot 75 \\
7 \cdot 25 \\
8 \cdot 30 \\
7 \cdot 70\end{array}$ & $\begin{array}{l}0.03155 \\
0.1350 \\
0 \cdot 2285 \\
0.2880\end{array}$ & $\begin{array}{l}0 \cdot 3628 \\
1 \cdot 562 \\
2717 \\
3 \cdot 441\end{array}$ & $\begin{array}{l}1.150 \times 10^{9} \\
1.157 " \Rightarrow \\
1.189 " \\
1.195 \Rightarrow\end{array}$ & $\begin{array}{l}1.152 \times 10^{9} \\
1.160 " \Rightarrow \\
1.190 " \Rightarrow \\
1.197 \Rightarrow\end{array}$ \\
\hline
\end{tabular}

52. In order to see whether any analogous effect would be produced by varnishing the wire, as was done in Joule's experiments (owing to possible diminution in rate of passage of heat from wire to water through diminished conducting-power of the varnish), a thin coat of clear filtered shell-lac varnish was lightly applied to the wire; and after two days drying, some of the observations were repeated, with the result of showing that whilst the effect of the varnishing was inappreciable with a weak current, it became noticeable with currents of 0.14 to 0.24 C.G.S. unit. To make sure that the resistance of the wire itself had not been altered permanently by strain \&c. during varnishing, the varnish was dissolved off by immersion in alcohol, after which the resistance-value again diminished to its former amount. Thus the following numbers were obtained:-

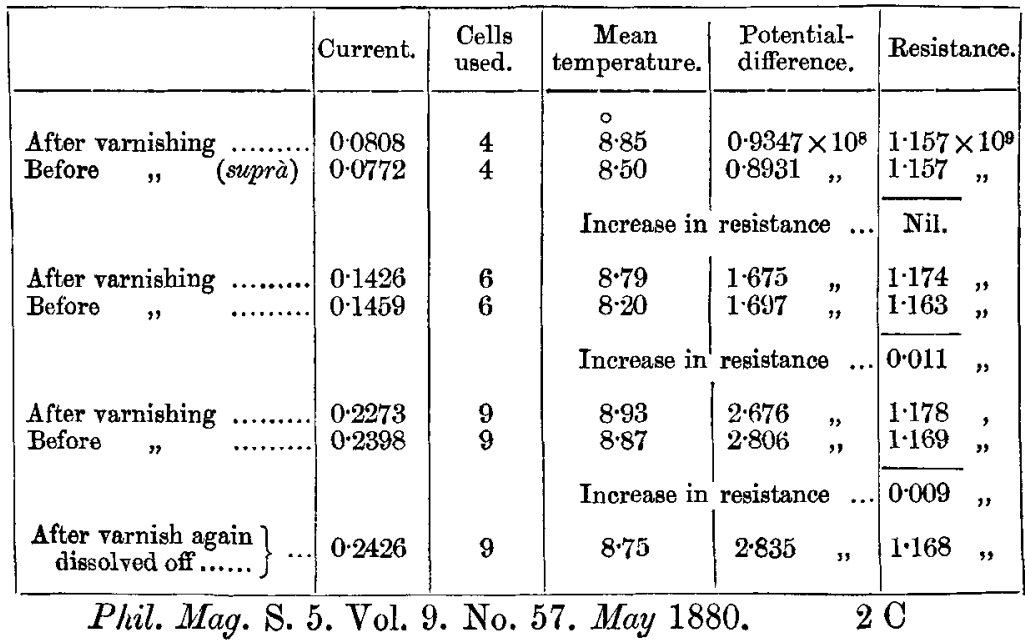




\section{Messrs. Wright and Rennie on the Determination of}

Apparently, therefore, with the stronger currents the varnish produced an increase in resistance about equal to that due to an increase in temperature of from $4^{\circ}$ to $5^{\circ}$; so that if the varnish in Joule's experiments produced a similar effect, the total superheating must have been near $12^{\circ}$ to $14^{\circ}$, representing 0.37 to 0.43 per cent. of error in deficiency in the estimation of $R$, and consequently of $J$.

53. Yet another source of error, and in the same direction, in these experiments of Joule's lies in the fact that, in comparing the resistances of the B.A. unit and the experimental wire employed, the method adopted consisted in determining the angular deflections $\alpha, \beta$, and $\gamma$ produced in a tangent-galvanometer on passing the current from a given electromotor (1) through the galvanometer only, (2) through the galvanometer and B.A.-unit coil, and (3) through the galvanometer and experimental wire-the resistance of the experimental wire being called $x$, and that of the unit coil $=1$,

$$
x=\frac{(\tan \alpha-\tan \gamma) \tan \beta}{(\tan \alpha-\tan \beta) \tan \gamma}
$$

Now, were the currents used so feeble that no appreciable amount of heat was developed by them in either wire, or were the two wires compared similarly sized and situated so as to be heated to equal extents, the value of $x$ thus deduced would be subject to no other errors than the instrumental and observational ones; but as the B.A.-unit-coil wires are imbedded in solid paraffin whilst the experimental wire was immersed naked in water (save for the film of varnish), it is evident that, if any heat at all had been generated by the currents employed, the B.A.-unit coil must have been more heated than the experimental wire, as the heat developed could not pass away readily through the badly conducting solid paraffin. The currents actually employed were sufficient to cause deflections of $36^{\circ}$ to $37^{\circ}$ with a galvanometer of nine turns and 17 inches diameter, and of $34^{\circ}$ to $50^{\circ}$ with a galvanometer of eighteen turns and 17 inches diameter; so that the currents were of magnitude equal to from

$$
\frac{17 \times 2 \cdot 54}{4 \pi \times 18} . I \tan 34 \text { to } \frac{17 \times 2 \cdot 54}{4 \pi \times 9} \times I \tan 37
$$

(where $I$ is the horizontal magnetic terrestrial force $=0 \cdot 18$, and 2.54 is the number of centims. in an inch), or averaged about 0.04 C.G.S. unit. In a wire of 1 B.A. unit resistance a current of this magnitude would produce per minute $0.04 \times 0.04 \times 10^{9} \times 60$ $42 \times 10^{6}=2 \cdot 3$ gramme-degrees, which, assuming 
the wire to weigh 10 grammes and to have the specific heat 0.04 (approximately that of an alloy of one part silver to two of platinum), would raise its temperature $\frac{2 \cdot 3}{10 \times 0 \cdot 04}$, or
nearly $6^{\circ}$ per minute.

It would therefore seem from this rough estimate that the heat-development produced in the B.A.-unit coil by the currents used may have been sufficient to raise its temperature perceptibly above that attributed to it; while the same result would not be produced to any thing like the same extent with the experimental wire, owing to the latter being immersed in water instead of solid paraffin. If it be assumed that this heatdevelopment sufficed to raise the average temperature of the B.A.-unit coil during the observations $5^{\circ}$ above that of the experimental wire (an amount of heating not at all unlikely to have occurred), the ultimate effect of this would be to cause the underestimation of $\mathrm{R}$, and consequently of $\mathrm{J}$, by $5 \times 0 \cdot 031=0 \cdot 15$ per cent.

54. Hence, finally, putting together this source of error and that due to the superheating of the wire (increased by varnishing), there is reason for supposing that the value of $J$ obtained by Joule in 1867 by the electric-current method may be at least 0.5 per cent. too small ; that is, instead of giving a value 1.31 per cent. larger than that deduced from Joule's waterfriction experiments of 1850 and 1878 (Part I. $\S 34$ ), the corrected value would probably be at least 1.8 per cent. larger than the water-friction value.

The practical conclusion to be drawn from these experiments, then, is that, in any determination in which it is necessary to pass a current through a wire for any length of time, an appreciable error, through increase in the resistance of the wire, will be brought about by its becoming superheated above the temperature of the medium in which it is placed when the current exceeds a certain limit, the exact value of which necessarily depends on the conditions. This source of error will affect determinations of E.M.F. made by such methods as those used by Latimer Clark in the valuation of his standard cell (Proc. Roy. Soc. xx. p. 444), and will similarly affect any experiments on the determination of $\mathrm{J}$ by methods based on the same principles as those involved in Joule's 1867 observations, unless the mode of experimenting be modified in such a way as to eliminate this source of error, or at least to render it negligible. We propose to examine certain such modifications which have occurred to us as being likely to reduce this source of error to an inconsiderable amount. 